\title{
Article \\ DRD4 Exon 3 Gene Polymorphisms in Patients Diagnosed with Polysubstance Use Disorder and Co-Occurrence of a Depressive Episode
}

\author{
Krzysztof Chmielowiec ${ }^{1}{ }^{(}$, Jolanta Chmielowiec ${ }^{1}{ }^{\circledR}$, Jolanta Masiak ${ }^{2}$, Małgorzata Czekaj ${ }^{3}$, Piotr Krawczyk $^{3}$, \\ Ewelina Soroka ${ }^{2}\left(\right.$, Małgorzata Śmiarowska ${ }^{4}$, Wojciech Musiał ${ }^{3}$, Tomasz Pawłowski ${ }^{5}{ }^{\circledR}$ and Anna Grzywacz ${ }^{6, *(1)}$ \\ 1 Department of Hygiene and Epidemiology, Collegium Medicum, University of Zielona Góra, 28 Zyty St., \\ 65-046 Zielona Góra, Poland; chmiele@vp.pl (K.C.); chmiele1@o2.pl (J.C.) \\ 2 Second Department of Psychiatry and Psychiatric Rehabilitation, Medical University of Lublin, 1 Głuska St., \\ 20-059 Lublin, Poland; jolanta.masiak@umlub.pl (J.M.); ewelina.soroka@umlub.pl (E.S.) \\ 3 Department of Nervous System Diseases, Orthopedics, Traumatology and Oncology of the Locomotor \\ System, Collegium Medicum, University of Zielona Góra, 28 Zyty St., 65-046 Zielona Góra, Poland; \\ vielgo@wp.pl (M.C.); krawczykp@poczta.onet.pl (P.K.); wojamus@wp.pl (W.M.) \\ 4 Department of Pharmacokinetics and Therapeutic Drug Monitoring, Pomeranian Medical University, \\ Aleja Powstanców Wlkp. 72 St., 70-111 Szczecin, Poland; malgorzata.smiarowska@wp.pl \\ 5 Division of Psychotherapy and Psychosomatic Medicine, Wroclaw Medical University, \\ Wyb. L. Pasteura 10 St., 50-367 Wroclaw, Poland; tomasz.pawlowski@umed.wroc.pl \\ check for \\ updates \\ Citation: Chmielowiec, K.; \\ 6 Independent Laboratory of Health Promotion, Pomeranian Medical University in Szczecin, \\ 11 Chlapowskiego St., 70-204 Szczecin, Poland \\ * Correspondence: grzywacz.anna.m@gmail.com; Tel.: +48-91441-47-46
}

Chmielowiec, J.; Masiak, J.; Czekaj,

M.; Krawczyk, P.; Soroka, E.;

Śmiarowska, M.; Musiał, W.;

Pawłowski, T.; Grzywacz, A. DRD4

Exon 3 Gene Polymorphisms in

Patients Diagnosed with

Polysubstance Use Disorder and Co-Occurrence of a Depressive

Episode. Genes 2021, 12, 1834

https://doi.org/10.3390/

genes12111834

Academic Editor: Paolo Cinelli

Received: 20 October 2021

Accepted: 19 November 2021

Published: 20 November 2021

Publisher's Note: MDPI stays neutral with regard to jurisdictional claims in published maps and institutional affiliations.

Copyright: (c) 2021 by the authors. Licensee MDPI, Basel, Switzerland. This article is an open access article distributed under the terms and conditions of the Creative Commons Attribution (CC BY) license (https:/ / creativecommons.org/licenses/by/ $4.0 /)$.

Abstract: Background: There has been a noticeable and systematic growth of the use of psychoactive substances over the past few decades. Dual diagnosis is a clinical term referring to the occurrence of psychoactive substance use disorder comorbid with another psychiatric disorder in the same person. The most common type of dual diagnosis is the co-occurrence of alcohol use disorder and mood disorders in the form of a depressive episode. Co-occurrent substance use disorders are frequently influenced by genetic factors. In selecting our area of research, we focused on dopamine and the DRD4 (Dopamine Receptor D4) gene polymorphism as well as associations with personality features. The aim of the study: The aim of the study was to compare DRD4 exon 3 (DRD4 Ex3) gene polymorphisms in patients diagnosed with polysubstance use disorder and co-occurrence of a depressive episode to $D R D 4$ exon 3 gene polymorphisms in patients diagnosed with polysubstance use disorder and without co-occurrence of a depressive episode and a group of healthy volunteers. The study also aimed at establishing associations between personality features and DRD4 exon 3 gene polymorphisms of male patients diagnosed with polysubstance use disorder with co-occurrence of a depressive episode which may present a specific endophenotype of this group of patients. Methods: The study group comprised 602 male volunteers: patients diagnosed with polysubstance use disorder comorbid with a depressive episode (PUD MDD) $(n=95$; mean age $=28.29$, standard deviation $(\mathrm{SD})=7.40)$, patients diagnosed with polysubstance use disorder (PUD) $(n=206$; mean age $=28.13$, $\mathrm{SD}=5.97)$, and controls $(n=301$; mean age $=22.13, \mathrm{SD}=4.57)$. The patients and control subjects were diagnosed by a psychiatrist using the Mini International Neuropsychiatric Interview (MINI), the NEO Five-Factor Personality Inventory (NEO-FFI), and the State-Trait Anxiety Inventory (STAI) questionnaires. An analysis of the DRD4 exon 3 polymorphism was performed. Results: The patients diagnosed with PUD MDD compared to the control group of healthy volunteers showed significantly higher scores on both the STAI status and features scale and the NEO-FFI Neuroticism and Openness Scale, as well as lower scores on the Extraversion, Agreeableness, and Conscientiousness NEO-FFI scales. In the DRD4 exon 3 gene polymorphism, the s allele was more frequent in the PUD MDD compared to the 1 allele, which was less frequent. The results of the $2 \times 3$ factor analysis of variance (ANOVA) in patients and controls and the variant DRD4 exon 3 interaction were found on the Extraversion Scale and the Conscientiousness Scale of the NEO-FFI. Conclusions: The associations show that psychological factors combined with genetic data create a new area of research on addiction, 
including the problem of dual diagnosis. However, we want to be careful and draw no definite conclusions at this stage of our research.

Keywords: addiction; dual diagnosis; DRD4 gene

\section{Introduction}

There has been a noticeable and systematic growth of the use of psychoactive substances over the past few decades [1]. Dual diagnosis is a clinical term referring to the occurrence of psychoactive substance use disorder comorbid with another psychiatric disorder in the same person [1]. The literature reports that approximately $50.9 \%$ of patients with psychiatric disorders are also diagnosed with psychoactive substance use disorder or alcohol use disorder [1]. Co-occurrent disorders are more frequently reported amongst males than females [2]. The most common type of dual diagnosis is the co-occurrence of alcohol use disorder and mood disorders in the form of a depressive episode [1]. Depression occurs 3-4 times more often in people with substance use disorders than in healthy controls [2,3]. If a depressive episode is severe, it largely anticipates faster development and maintenance of substance use disorder [2]. The occurrence of dual diagnosis in patients makes the treatment process more difficult both in terms of pharmacotherapy and psychotherapy [2] and may also contribute to a more frequent occurrence of suicidality.

Therefore, our study focused on a group of patients suffering from polysubstance use disorder who also had comorbid diagnosis of a depressive episode, and the study aimed at comparing DRD4 exon 3 gene polymorphisms in patients diagnosed with polysubstance use disorder and co-occurrence of a depressive episode to DRD4 exon 3 gene polymorphisms in patients diagnosed with polysubstance use disorder and without cooccurrence of a depressive episode, and a group of healthy volunteers. The study also aimed at establishing associations between personality features and DRD4 exon 3 gene polymorphisms of male patients diagnosed with polysubstance use disorder with cooccurrence of a depressive episode, which may present a specific endophenotype of this group of patients.

Co-occurrent substance use disorders are frequently influenced by genetic factors [4]. In selecting our area of research, we focused on dopamine and the DRD4 gene (dopamine receptor $\mathrm{D} 4$ gene).

Several clinical genetic linkage studies demonstrate possible correlations between DRD4 expression and substance use disorders, as well as depression [5]. Carriers of the DRD4 7R allele showed greater susceptibility to alcohol use disorder and opioid use disorder [5]. The inconsistency in studies on relations between DRD4 polymorphisms and dependencies suggests focusing on addiction-related phenotypes rather than on a diagnosis of dependency itself.

The DRD4 gene is located in chromosome 11p, close to the telomere. It encodes the 7-transmembrane $G$ protein-coupled receptor that responds to endogenous dopamine [6-8]. The exon 3 seven-repeat (7R) allele of $D R D 4$ codes for a decreased dopamine receptor affinity and is associated with frequent substance abuse [9].

The existing research on the role of the DRD4 (VNTR) polymorphism for somebody's personality is inconclusive [10]. The allelic variation in the DRD4 dopamine gene has been associated with novelty seeking [10] and impulsivity [11]. These results thus confirmed previous findings in which the long repeats of the DRD4 exon 3 polymorphism were related to the novelty-seeking personality trait. In the existing research, attempts are made to recognize associations between the DRD4 (VNTR) polymorphism and extraversion [12-16]. In a comprehensive metanalysis, substance use disorder was associated with high disinhibition, low conscientiousness and low agreeableness, but it was not significantly associated with neuroticism and extraversion [17]. The lack of knowledge in the field of personality features of patients diagnosed with polysubstance use disorder and cooccurrence 
of a depressive episode as well as associations of these factors with $D R D 4$ exon 3 gene polymorphisms inspired us to undertake this research.

\section{Materials and Methods}

\subsection{Materials}

The study group of 602 male volunteers comprised patients diagnosed with polysubstance use disorder comorbid with a depressive episode (PUD MDD; $n=95$; mean age $=28.29$, $\mathrm{SD}=7.40$ ), patients diagnosed with polysubstance use disorder (PUD; $n=206$; mean age $=28.13, \mathrm{SD}=5.97)$ and healthy controls $(n=301$; mean age $=22.13, \mathrm{SD}=4.57)$. The distribution of particular types of substance use disorder in the study group is presented as percentages in Table 1. After the approval of the Bioethics Committee of the Pomeranian Medical University in Szczecin (KB-0012/106/16) and when the written informed consent of the participants had been gained, the study was carried out in the Independent Laboratory of Health Promotion. After at least three months of abstinence in addiction treatment facilities, the patients with polysubstance use disorder (PUD) and patients with polysubstance use disorder comorbid with a depressive episode (PUD MDD) were recruited for the study. The patients with polysubstance use disorder (PUD) and polysubstance use disorder comorbid with a depressive episode (PUD MDD) as well as the control subjects were interviewed by a psychiatrist using the Mini International Neuropsychiatric Interview (MINI), the NEO Five-Factor Personality Inventory (NEO-FFI), and the State-Trait Anxiety Inventory (STAI).

Table 1. Type of psychoactive substance use in addicts.

\begin{tabular}{ccc}
\hline Type of Substance/Addiction & All Patients Diagnosed with PUD MDD $(\boldsymbol{n}=\mathbf{9 5})$ \\
\hline & $n$ & $\%$ \\
Behavioral addiction & 43 & 45.3 \\
Designer drugs & 21 & 22.1 \\
F10.2-alcohol & 56 & 58.9 \\
F11.2-opiates & 21 & 22.1 \\
F12.2-cannabinols & 69 & 72.6 \\
F13.2- sedatives and hypnotics & 14 & 14.7 \\
F14.2-cocaine & 8 & 8.4 \\
F15.2-stimulants & 78 & 82.1 \\
F16.2-hallucinogenic & 13 & 13.7 \\
F19.2-mixed addictions & 60 & 63.2 \\
\hline
\end{tabular}

Interactions between personality traits and $D R D 4$ exon 3 gene polymorphisms were examined only for the group of patients diagnosed with PUD MDD and non-dependent controls.

\subsection{Measures}

The MINI is a structured diagnostic interview, developed to assess the diagnoses of psychiatric patients according to DSM-IV and ICD-10 criteria. In our investigation, the study group and control subjects were examined by a psychiatrist using the MINI.

The STAI measures anxiety as a trait of anxiety (A-Trait) that can be described as an enduring predisposition to having worries, stress, and discomfort and anxiety states (A-states), such as uneasiness, fear, and temporary stimulation of the autonomic nervous system in response to certain circumstances.

The Personality Inventory (NEO Five-Factor Inventory, NEO-FFI) incorporates 6 components for each of the five traits-neuroticism (anxiety, hostility, depression, selfconsciousness, impulsiveness, vulnerability to stress), extraversion (warmth, gregariousness, assertiveness, activity, excitement seeking, positive emotion), openness to experience (fantasy, aesthetics, feelings, actions, ideas, values), agreeableness (trust, straightforwardness, altruism, compliance, modesty, tendermindedness), and conscientiousness (competence, order, dutifulness, achievement striving, self-discipline, deliberation) [18]. 
The results delivered by the inventories, i.e., NEO-FFI and STAI, were returned as sten scores. For the conversion of raw results into the sten scale scores, which was performed according to the Polish norms regarding adults, it was assumed that 1-2 accounted for very low scores, 3-4 accounted for low scores, 5-6 accounted for average scores, 7-8 accounted for high scores, and 9-10 accounted for very high scores.

\subsection{Genotyping}

Tubes containing EDTA (anticoagulant) were used for collecting blood for genetic assays. Genomic DNA from blood leukocytes was obtained using the High Pure Polymerase Chain Reaction (PCR) Template Preparation extraction kit (Roche Diagnostics, Mannheim, Germany). The process of extraction was performed according to the manufacturer's instructions. The extracted samples of DNA had been stored at $4^{\circ} \mathrm{C}$ before further analysis was carried out.

The genomic DNA was sourced from venous blood drawn according to standard procedures. In order to genotype the samples, the PCR method was used. The DRD4 genotypes were grouped based on the presence of the short (2-5 repeat) and long (6-11 repeat) variants. Genotyping was conducted using the PCR-VNTR method and included the following primers: F: 5 0-GCG ACT ACG TGG TCT ACT CG 3 0, R: 5 0-AGG ACC CTC ATG GCC TTG 3 0; in the final volume of $25 \mu \mathrm{L}$ PCR mix per reaction, with $100 \mathrm{ng}$ of genomic DNA, 10 pmol of primers, $50 \mathrm{mM} \mathrm{KCl}, 10 \mathrm{mM}$ TrisHCl, $1.5 \mathrm{mM} \mathrm{MgCl} 2,200 \mu \mathrm{M}$ $\mathrm{dATP}, \mathrm{dCTP}, \mathrm{dTTP}, \mathrm{dGTP}$, and $0.8 \mathrm{U}$ of the Tag polymerase. The reaction occurred under the following conditions: 3 min of initial denaturation at $95^{\circ} \mathrm{C}$, cycles of denaturation at $95^{\circ} \mathrm{C}$ for $30 \mathrm{~s}$, hybridization of primers at $63^{\circ} \mathrm{C}$ for $1 \mathrm{~min}$, and elongation at $72{ }^{\circ} \mathrm{C}$ for $30 \mathrm{~s}$, repeated in 35 cycles, with final elongation at $72{ }^{\circ} \mathrm{C}$ for $5 \mathrm{~min}$. The amplified products were visualized using ethidium bromide-stained gel electrophoresis ( $3 \%$ agarose) and UV photography. The products ranged from $379 \mathrm{bp}$ ( 2 repeats) to 811 (11 repeats) and were divided into 2 groups: short alleles (S, $2-5$ repeats) and long alleles ( $L, 6-11$ repeats).

\subsection{Statistical Analysis}

Concordance between the genotype frequency distribution and Hardy-Weinberg equilibrium (HWE) was verified using the HWE software (https: / / wpcalc.com/en/equilibriumhardy-weinberg/ (20 March 2021)). The relationships between DRD4 exon 3 (DRD4 Ex3) variants, PUD, PUD MDD, control subjects, and the NEO Five Factor Inventory (NEO-FFI) were analyzed using a multivariate analysis of factor effects ANOVA [NEO-FFI/scale $\mathrm{STAI} / \times$ genetic feature $\times$ control and PUD and PUD MDD $\times$ (genetic feature $\times$ control and PUD/PUD MDD)]. The condition of homogeneity of variance was fulfilled (Levene test $p>0.05$ ). The analyzed variables were not distributed normally. The NEO Five Factor Inventory (neuroticism, extraversion, openness, agreeability, and conscientiousness) was applied and compared using the Mann-Whitney U-test. DRD4 exon 3 genotype frequencies between the healthy control subjects and PUD MDD and PUD subjects were established using the chi-square test. All computations were made using STATISTICA 13 (Tibco Software Inc., Palo Alto, CA, USA) for Windows (Microsoft Corporation, Redmond, WA, USA).

\section{Results}

For the patients diagnosed with PUD MDD, PUD, and control subjects, the frequency distributions accorded with the HWE (Table 2).

No difference for $D R D 4$ exon 3 (Ex3) genotype frequencies in the sample group was found between patients diagnosed with PUD MDD, patients diagnosed with PUD, and control subjects (Table 3).

The means and standard deviations for all the NEO Five Factor Inventory results and the STAI scale state and trait scale variant interactions for the PUD MDD and PUD and control subjects are presented in Table 4 . 
Table 2. Hardy-Weinberg's law for patients with polysubstance use disorder comorbid with a depressive episode (PUD MDD), for patients diagnosed with polysubstance use disorder (PUD) and control subjects.

\begin{tabular}{|c|c|c|c|c|c|}
\hline \multirow{2}{*}{\multicolumn{2}{|c|}{$\begin{array}{l}\text { Hardy-Weinberg Equilibrium Calculator } \\
\text { Including Analysis for Ascertainment Bias }\end{array}$}} & \multirow{2}{*}{$\begin{array}{l}\text { Observed } \\
\text { (Expected) }\end{array}$} & & \multicolumn{2}{|c|}{ Test $\chi^{2}$} \\
\hline & & & & $x^{2}$ & $p$ \\
\hline DRD4 Ex3 PUD MDD & $\begin{array}{l}\mathrm{s} / \mathrm{s} \\
\mathrm{s} / 1 \\
1 / 1\end{array}$ & $\begin{array}{c}63(64) \\
30(27.9) \\
2(3)\end{array}$ & $\begin{array}{l}1 \text { allele freq }=0.18 \\
\mathrm{~s} \text { allele freq }=0.82\end{array}$ & 0.529 & $>0.05$ \\
\hline DRD4 Ex3 PUD & $\begin{array}{l}\mathrm{s} / \mathrm{s} \\
\mathrm{s} / 1 \\
1 / 1\end{array}$ & $\begin{array}{c}127(128.2) \\
71(68.6) \\
8(9.2)\end{array}$ & $\begin{array}{l}1 \text { allele freq }=0.21 \\
\mathrm{~s} \text { allele freq }=0.79\end{array}$ & 0.245 & $>0.05$ \\
\hline DRD4 Ex3 control subjects & $\begin{array}{l}\mathrm{s} / \mathrm{s} \\
\mathrm{s} / 1 \\
1 / 1\end{array}$ & $\begin{array}{c}177(169.7) \\
98(112.6) \\
26(18.7)\end{array}$ & $\begin{array}{l}1 \text { allele freq }=0.25 \\
\mathrm{~s} \text { allele freq }=0.75\end{array}$ & 5.075 & $<0.05$ \\
\hline
\end{tabular}

Table 3. Frequency of genotypes of $D R D 4$ exon 3 (Ex3) gene polymorphisms in patients diagnosed with PUD MDD, patients diagnosed with PUD, and control subjects.

\begin{tabular}{|c|c|c|c|c|c|}
\hline \multirow{3}{*}{ Group } & \multicolumn{5}{|c|}{ DRD4 Ex3 } \\
\hline & \multicolumn{3}{|c|}{ Genotypes } & \multicolumn{2}{|c|}{ Alleles } \\
\hline & $\begin{array}{c}\mathrm{s} / \mathrm{s} \\
n(\%)\end{array}$ & $\begin{array}{c}\mathrm{s} / 1 \\
n(\%)\end{array}$ & $\begin{array}{c}1 / 1 \\
n(\%)\end{array}$ & $\begin{array}{c}\mathrm{s} \\
n(\%)\end{array}$ & $\begin{array}{c}1 \\
n(\%)\end{array}$ \\
\hline A: PUD MDD & 63 & 30 & 2 & 156 & 34 \\
\hline$n=95$ & (66) & (32) & (2) & $(82)$ & (18) \\
\hline B: PUD & 127 & 71 & 8 & 325 & 87 \\
\hline$n=206$ & (62) & (34) & (4) & (79) & $(21)$ \\
\hline \multirow{2}{*}{$\begin{array}{c}\text { C: Control } \\
n=301\end{array}$} & 177 & 98 & 26 & 452 & 150 \\
\hline & (59) & (33) & (9) & $(75)$ & $(25)$ \\
\hline \multirow{3}{*}{$\chi^{2}(p$ value $)$} & \multicolumn{3}{|c|}{ A/B: 1.01 (0.605) } & \multicolumn{2}{|c|}{ A/B: $0.84(0.359)$} \\
\hline & \multicolumn{3}{|c|}{ A/C: 5.05 (0.079) } & \multicolumn{2}{|c|}{ A/C: $3.99\left(0.046^{*}\right)$} \\
\hline & \multicolumn{3}{|c|}{ B/C: $4.42(0.110)$} & \multicolumn{2}{|c|}{ B/C: $1.970(0.160)$} \\
\hline
\end{tabular}

Table 4. STAI and NEO Five Factor Inventory sten scores between healthy controls and all patients diagnosed with polysubstance use disorder comorbid with a depressive episode (PUD MDD) and all patients diagnosed with polysubstance use disorder comorbid with a depressive episode (PUD).

\begin{tabular}{|c|c|c|c|c|c|c|}
\hline $\begin{array}{l}\text { STAI/NEO Five Factor } \\
\text { Inventory/ }\end{array}$ & $\begin{array}{c}\text { A: } \\
\text { PUD MDD } \\
(n=95)\end{array}$ & $\begin{array}{c}\text { B: } \\
\text { PUD } \\
(n=206)\end{array}$ & $\begin{array}{c}\text { C: } \\
\text { Control } \\
(n=301)\end{array}$ & $\begin{array}{c}\text { A/C: } \\
\mathrm{Z} \\
(p \text {-Value })\end{array}$ & $\begin{array}{c}\text { B/C: } \\
\mathrm{Z} \\
(p \text {-Value })\end{array}$ & $\begin{array}{c}\text { A/B: } \\
Z \\
(p-\text { Value })\end{array}$ \\
\hline STAI trait/scale & $7.62 \pm 2.25$ & $6.87 \pm 2.25$ & $5.16 \pm 2.17$ & $\begin{array}{c}7.062 \\
(0.0000 *)\end{array}$ & $\begin{array}{c}7.768 \\
(0.0000 *)\end{array}$ & $\begin{array}{c}3.665 \\
(0.0002 *)\end{array}$ \\
\hline STAI state/scale & $6.65 \pm 2.21$ & $5.54 \pm 2.43$ & $4.68 \pm 2.14$ & $\begin{array}{c}8.207 \\
(0.0000 *)\end{array}$ & $\begin{array}{c}4.162 \\
(0.0000 *)\end{array}$ & $\begin{array}{c}2.754 \\
(0.0059 *)\end{array}$ \\
\hline Neuroticism/scale & $7.34 \pm 2.00$ & $6.45 \pm 2.20$ & $4.67 \pm 2.01$ & $\begin{array}{c}9.264 \\
(0.0000 *)\end{array}$ & $\begin{array}{c}8.683 \\
(0.0000 *)\end{array}$ & $\begin{array}{c}3.094 \\
(0.0020 *)\end{array}$ \\
\hline Extraversion/scale & $5.44 \pm 2.36$ & $5.90 \pm 2.01$ & $6.37 \pm 1.97$ & $\begin{array}{c}-3.640 \\
(0.0003 *)\end{array}$ & $\begin{array}{c}-2.412 \\
\left(0.0147^{*}\right)\end{array}$ & $\begin{array}{l}-1.837 \\
(0.0602)\end{array}$ \\
\hline Openness/scale & $5.46 \pm 2.01$ & $4.80 \pm 2.00$ & $4.53 \pm 1.61$ & $\begin{array}{c}4.136 \\
(0.0000 *)\end{array}$ & $\begin{array}{c}1.401 \\
(0.1545)\end{array}$ & $\begin{array}{c}2.557 \\
\left(0.0106^{*}\right)\end{array}$ \\
\hline Agreeability/scale & $4.05 \pm 1.99$ & $4.41 \pm 1.90$ & $5.60 \pm 2.09$ & $\begin{array}{c}-6.286 \\
(0.0000 *)\end{array}$ & $\begin{array}{c}-6.165 \\
(0.0000 *)\end{array}$ & $\begin{array}{c}-1.959 \\
(0.0501 *)\end{array}$ \\
\hline Conscientiousness/scale & $5.01 \pm 2.14$ & $5.85 \pm 2.29$ & $6.07 \pm 2.15$ & $\begin{array}{c}-4.102 \\
(0.0000 *)\end{array}$ & $\begin{array}{l}-1.014 \\
(0.3059)\end{array}$ & $\begin{array}{c}-3.006 \\
(0.0027 *)\end{array}$ \\
\hline
\end{tabular}

$p$, statistical significance with Mann-Whitney U-test; $n$, number of subjects; $\mathrm{M} \pm \mathrm{SD}$, mean \pm standard deviation; * statistically significant differences. 
Compared to the control group, no statistically significant difference in the genotype frequency for the DRD4 exon 3 (Ex3) gene in the patients diagnosed with PUD MDD and patients diagnosed with PUD was found. A statistically significant difference was found in the frequency of $D R D 4$ exon 3 (Ex3) alleles between all patients diagnosed with PUD MDD and the control group (s 0.82 vs. $0.75,10.18$ vs. $0.25, \chi^{2}=3.99, p=0.046$ ).

While comparing the controls and the PUD MDD subjects, for the latter, we found significantly higher scores on the STAI trait scale (M 7.62 vs. M 5.16, $p<0.001$ ), the STAI state scale (M 6.65 vs. M 4.68, $p<0.001$ ), the NEO Five Factor Inventory Scale of Neuroticism (M 7.34 vs. M 4.67, $p<0.001$ ), and the NEO Five Factor Inventory Scale of Openness (M 5.46 vs. M 4.53, $p<0.001$ ).

Compared to the controls, the case group subjects had significantly lower scores on the NEO Five Factor Inventory Scale of Extraversion (M 5.44 vs. M 6.37, $p<0.001$ ), the NEO Five Factor Inventory Scale of Agreeability (M 4.05 vs. M 5.60, $p<0.001$ ), and the NEO Five Factor Inventory Scale of Conscientiousness (M 5.01 vs. M 6.07, $p<0.001$ ).

Regarding the controls and PUD subjects, for the latter, we found significantly higher scores on the STAI trait scale (M 6.87 vs. M 5.16, $p<0.001$ ), the STAI state scale (M 5.54 vs. M 4.68, $p<0.001$ ), and the NEO Five Factor Inventory Scale of Neuroticism (M 6.45 vs. $\mathrm{M} 4.67, p<0.001$ ).

Compared to the controls, the case group subjects had significantly lower scores on the NEO Five Factor Inventory Scale of Extraversion (M 5.90 vs. M 6.37, $p=0.0147$ ) and the NEO Five Factor Inventory Scale of Agreeability (M 4.41 vs. M 5.60, $p<0.001$ ).

Regarding the PUD MDD subjects and PUD subjects, for the latter, we found significantly higher scores on the STAI trait scale (M 7.62 vs. M $6.87, p=0.0002)$, the STAI state scale (M 6.65 vs. M 5.54, $p=0.0059$ ), and the NEO Five Factor Inventory Scale of Neuroticism (M 7.34 vs. M 5.85, $p=0.002$ ).

Compared to the controls, the case group subjects had significantly lower scores on the NEO Five Factor Inventory Scale of Conscientiousness (M 5.01 vs. M 6.37, $p=0.0027$ ).

The results of the $2 \times 3$ factorial ANOVA of the NEO Five-Factor Personality Inventory (NEO-FFI) and the State-Trait Anxiety Inventory (STAI) sten scales are summarized in Tables 5 and 6.

No statistically significant differences were found between the groups (PUD/PUD MDD vs. controls) on the NEO FFI scale, or alleles s and 1 DRD4 exon 3 (Ex3).

No statistically significant differences were found between the groups (PUD vs. controls) on the NEO FFI Extraversion Scale and the polymorphism of the DRD4 exon 3 (Ex3) gene.

We received a significant result for DRD4 exon 3 (Ex3) $\left(\mathrm{F}_{2,389}=6.23, p=0.002\right)$ on the NEO-FFI Extraversion Scale, which accounted for $3.1 \%$ of the variance. With regard to interactions, we found a significant result for the groups (PUD MDD vs. controls) on the NEO FFI Extraversion Scale, and DRD4 exon 3 (Ex3) (Figure 1, $\mathrm{F}_{2,389}=4.22, p=0.015$ ) accounted for $2.1 \%$ of the variance (Table 5). The results of the post hoc test are shown in Table 7.

We found a significant result for DRD4 exon $3(\mathrm{Ex} 3)\left(\mathrm{F}_{2,389}=5.09, p=0.007\right)$ on the NEO-FFI Conscientiousness Scale, which accounted for $2.6 \%$ of the variance. With regard to interactions, we received a significant result for the groups (PUD MDD vs. controls) on the NEO FFI Conscientiousness Scale, and DRD4 exon 3 (Ex3) (Figure 2, $\mathrm{F}_{2,389}=5.24$, $p=0.006$ ) accounted for $2.6 \%$ of the variance (Table 5). The results of the post hoc test are shown in Table 7. 
Table 5. Differences in DRD4 exon 3 (DRD4 Ex3), the NEO Five Factor Inventory, and the STAI scale between healthy controls and PUD MDD subjects.

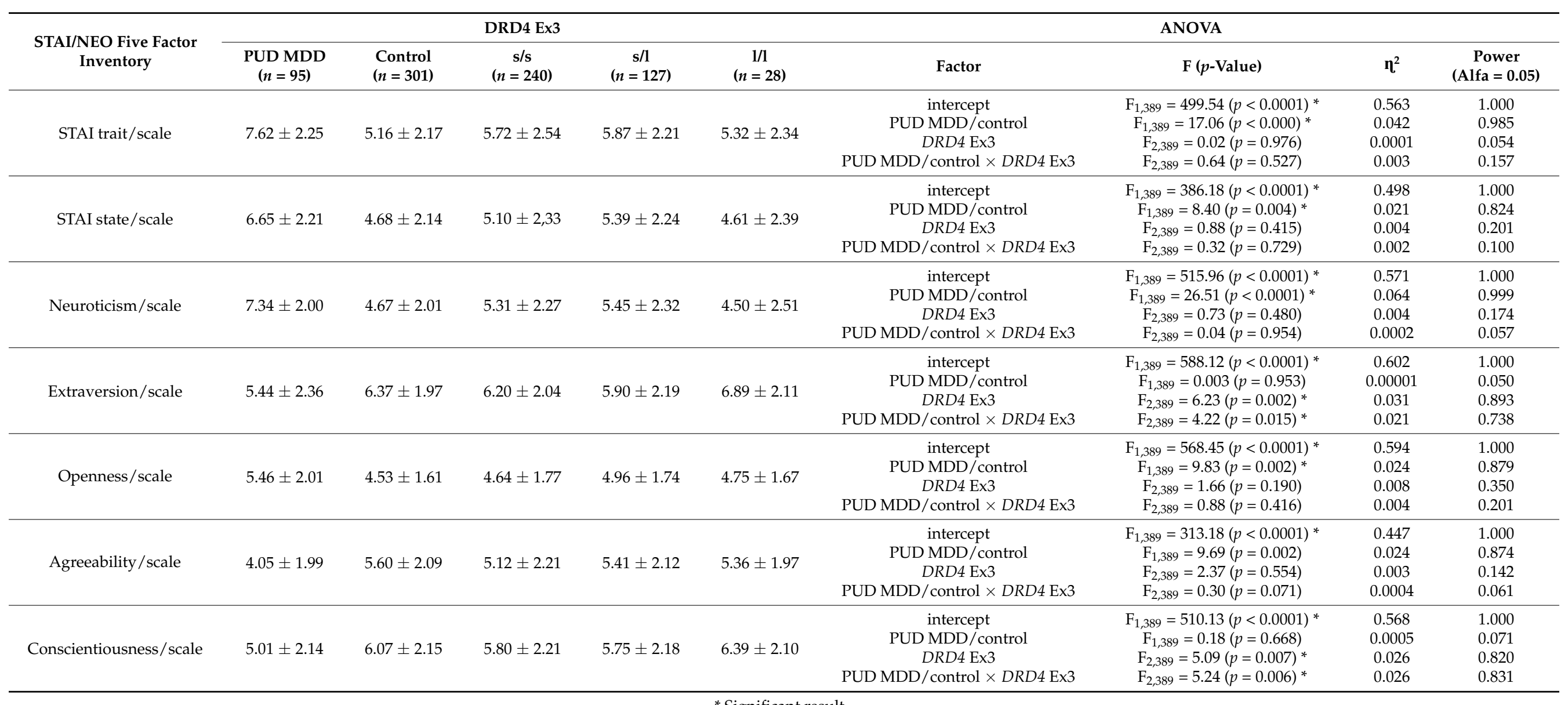


Table 6. Differences in DRD4 exon 3 (DRD4 Ex3), the NEO Five Factor Inventory, the STAI scale between healthy controls and PUD subjects.

\begin{tabular}{|c|c|c|c|c|c|c|c|c|c|}
\hline \multirow{2}{*}{$\begin{array}{l}\text { STAI/NEO Five Factor } \\
\text { Inventory }\end{array}$} & \multicolumn{5}{|c|}{ DRD4 Ex3 } & \multicolumn{4}{|c|}{ ANOVA } \\
\hline & $\begin{array}{c}\text { PUD } \\
(n=206)\end{array}$ & $\begin{array}{l}\text { Control } \\
(n=301)\end{array}$ & $\begin{array}{c}\mathrm{s} / \mathrm{s} \\
(n=304)\end{array}$ & $\begin{array}{c}\mathrm{s} / 1 \\
(n=169)\end{array}$ & $\begin{array}{c}1 / 1 \\
(n=34)\end{array}$ & Factor & F ( $p$-Value) & $\eta^{2}$ & $\begin{array}{c}\text { Power } \\
(\text { Alfa }=0.5)\end{array}$ \\
\hline STAI trait/scale & $6.87 \pm 2.25$ & $5.16 \pm 2.17$ & $5.83 \pm 2.49$ & $6.00 \pm 2.16$ & $5.29 \pm 2.14$ & $\begin{array}{c}\text { intercept } \\
\text { PUD/control } \\
D R D 4 \text { Ex3 } \\
\text { PUD/control x DRD4 Ex3 }\end{array}$ & $\begin{array}{c}\mathrm{F}_{1,501}=1255.43(p<0.0001) * \\
\mathrm{~F}_{1,501}=15.92(p<0.0001) * \\
\mathrm{~F}_{2,501}=0.98(p=0.375) \\
\mathrm{F}_{2,501}=1.52(p=0.219)\end{array}$ & $\begin{array}{l}0.716 \\
0.031 \\
0.004 \\
0.006 \\
\end{array}$ & $\begin{array}{l}1.000 \\
0.978 \\
0.221 \\
0.324 \\
\end{array}$ \\
\hline STAI state/scale & $5.54 \pm 2.43$ & $4.68 \pm 2.14$ & $4.99 \pm 2.30$ & $5.21 \pm 2.27$ & $4.50 \pm 2.40$ & $\begin{array}{c}\text { intercept } \\
\text { PUD/control } \\
D R D 4 \text { Ex3 } \\
\text { PUD/control x DRD4 Ex3 }\end{array}$ & $\begin{array}{c}\mathrm{F}_{1,501}=849.36(p<0.0001) * \\
\mathrm{~F}_{1,501}=2.14(\mathrm{p}=0.144) \\
\mathrm{F}_{2,501}=1.41(p=0.245) \\
\mathrm{F}_{2,501}=1.21(p=0.299)\end{array}$ & $\begin{array}{l}0.630 \\
0.004 \\
0.006 \\
0.005\end{array}$ & $\begin{array}{l}1.000 \\
0.309 \\
0.303 \\
0.264 \\
\end{array}$ \\
\hline Neuroticism/scale & $6.45 \pm 2.20$ & $4.67 \pm 2.01$ & $5.46 \pm 2.29$ & $5.39 \pm 2.16$ & $4.67 \pm 2.43$ & $\begin{array}{c}\text { intercept } \\
\text { PUD/control } \\
D R D 4 \text { Ex3 } \\
\text { PUD/control x DRD4 Ex3 }\end{array}$ & $\begin{array}{c}\mathrm{F}_{1,501}=1196.67(p<0.0001)^{*} \\
\mathrm{~F}_{1,501}=27.48(p<0.0001)^{*} \\
\mathrm{~F}_{2,501}=0.82(p=0.442) \\
\mathrm{F}_{2,501}=1.31(p=0.270)\end{array}$ & $\begin{array}{l}0.705 \\
0.052 \\
0.003 \\
0.005\end{array}$ & $\begin{array}{l}1.000 \\
0.999 \\
0.190 \\
0.284\end{array}$ \\
\hline Extraversion/scale & $5.90 \pm 2.01$ & $6.37 \pm 1.97$ & $6.15 \pm 1.98$ & $6.11 \pm 2.03$ & $6.76 \pm 2.05$ & $\begin{array}{c}\text { intercept } \\
\text { PUD/control } \\
D R D 4 \text { Ex3 } \\
\text { PUD/control x DRD4 Ex3 }\end{array}$ & $\begin{array}{c}\mathrm{F}_{1,501}=1803.32(p<0.0001) * \\
\mathrm{~F}_{1,501}=0.73(p=0.391) \\
\mathrm{F}_{2,501}=1.45(p=0.234) \\
\mathrm{F}_{2,501}=0.34(p=0.713)\end{array}$ & $\begin{array}{l}0.782 \\
0.001 \\
0.005 \\
0.001 \\
\end{array}$ & $\begin{array}{l}1.000 \\
0.137 \\
0.311 \\
0.104 \\
\end{array}$ \\
\hline Openness/scale & $4.80 \pm 2.00$ & $4.53 \pm 1.61$ & $4.51 \pm 1.74$ & $4.84 \pm 1.82$ & $4.85 \pm 1.89$ & $\begin{array}{c}\text { intercept } \\
\text { PUD/control } \\
D R D 4 \text { Ex3 } \\
\text { PUD/control x DRD4 Ex3 }\end{array}$ & $\begin{array}{c}\mathrm{F}_{1,501}=1335.71(p<0.0001) * \\
\mathrm{~F}_{1,501}=3.99(p=0.046) \\
\mathrm{F}_{2,501}=2.61(p=0.0740) \\
\mathrm{F}_{2,501}=0.99(p=0.372)\end{array}$ & $\begin{array}{l}0.727 \\
0.008 \\
0.010 \\
0.003\end{array}$ & $\begin{array}{l}1.000 \\
0.514 \\
0.520 \\
0.222\end{array}$ \\
\hline Agreeability/scale & $4.41 \pm 1.90$ & $5.60 \pm 2.09$ & $5.09 \pm 2.12$ & $5.22 \pm 2.00$ & $4.82 \pm 2.25$ & $\begin{array}{c}\text { intercept } \\
\text { PUD/control } \\
D R D 4 \text { Ex3 } \\
\text { PUD/control x DRD4 Ex3 }\end{array}$ & $\begin{array}{c}\mathrm{F}_{1,501}=993.33(p<0.0001) \\
\mathrm{F}_{1,501}=33.04(p<0.0001) \\
\mathrm{F}_{2,501}=2.95(p=0.053) \\
\mathrm{F}_{2,501}=2.30(p=0.101)\end{array}$ & $\begin{array}{l}0.665 \\
0.061 \\
0.012 \\
0.009\end{array}$ & $\begin{array}{l}1.000 \\
0.999 \\
0.574 \\
0.468\end{array}$ \\
\hline Conscientiousness/scale & $5.85 \pm 2.29$ & $6.07 \pm 2.15$ & $5.93 \pm 2.27$ & $6.01 \pm 2.14$ & $6.26 \pm 1.94$ & $\begin{array}{c}\text { intercept } \\
\text { PUD/control } \\
D R D 4 \mathrm{Ex3} \\
\text { PUD/control x DRD4 Ex3 }\end{array}$ & $\begin{array}{c}\mathrm{F}_{1,501}=1357.97(p<0.0001) * \\
\mathrm{~F}_{1,501}=0.002(p=0.961) \\
\mathrm{F}_{2,501}=0.53(p=0.587) \\
\mathrm{F}_{2,501}=0.31(p=0.729)\end{array}$ & $\begin{array}{c}0.730 \\
0.00001 \\
0.002 \\
0.001\end{array}$ & $\begin{array}{l}1.000 \\
0.050 \\
0.138 \\
0.100\end{array}$ \\
\hline
\end{tabular}


$\mathrm{F}_{2,389}=4.22, p=0.015$

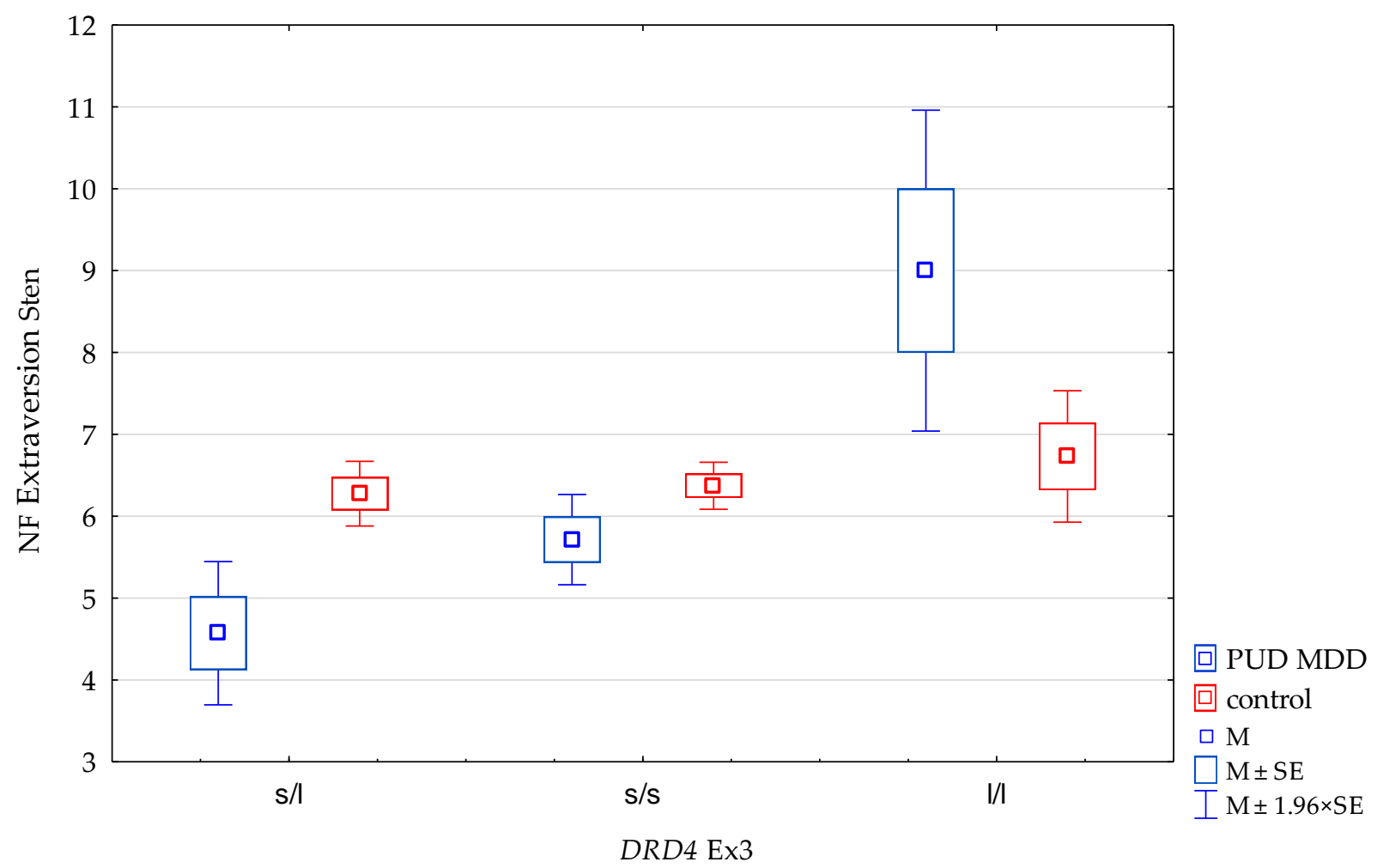

Figure 1. Interaction between patients with polysubstance use disorder comorbid with a depressive episode (PUD MDD)/control and DRD4 exon 3 (DRD4 Ex3) and the NEO FFI Extraversion Scale. M, mean; SE, standard error.

Table 7. Post hoc analysis of interactions between patients with polysubstance use disorder comorbid with a depressive episode (PUD MDD)/control and DRD4 exon 3 (DRD4 Ex3) and the NEO FFI Extraversion/Conscientiousness Scale.

\begin{tabular}{|c|c|c|c|c|c|c|}
\hline \multicolumn{7}{|c|}{ DRD4Ex3 and NEO FFI Extraversion Scale } \\
\hline & $\begin{array}{c}\{1\} \\
M=4.57\end{array}$ & $\begin{array}{c}\{2\} \\
M=5.71\end{array}$ & $\begin{array}{c}\{3\} \\
M=9.00\end{array}$ & $\begin{array}{c}\{4\} \\
M=6.28\end{array}$ & $\begin{array}{c}\{5\} \\
M=6.37\end{array}$ & $\begin{array}{c}\{6\} \\
M=6.73\end{array}$ \\
\hline PUD MDD DRD4 Ex3 s $/ 1\{1\}$ & & $0.0145^{*}$ & 0.0033 * & $0.0001 *$ & $<0.0000 *$ & $0.0001 *$ \\
\hline PUD MDD DRD4 Ex3 s/s $\{2\}$ & & & $0.0261 *$ & 0.0905 & $0.0290 *$ & 0.0339 * \\
\hline PUD MDD DRD4 Ex3 1/1 \{3\} & & & & 0.0633 & 0.0720 & 0.1319 \\
\hline control DRD4 Ex3 s/1 $\{4\}$ & & & & & 0.7060 & 0.3143 \\
\hline control DRD4 Ex3 s/s $\{5\}$ & & & & & & 0.4060 \\
\hline control DRD4 Ex3 1/1 $\{6\}$ & & & & & & \\
\hline \multicolumn{7}{|c|}{ DRD4Ex3 and NEO FFI Conscientiousness Scale } \\
\hline & $\{\mathbf{1}\}$ & $\{2\}$ & $\{3\}$ & $\{4\}$ & $\{5\}$ & $\{6\}$ \\
\hline & $\mathrm{M}=4.39$ & $M=5.14$ & $\mathrm{M}=9.50$ & $M=6.13$ & $M=6.04$ & $M=6.15$ \\
\hline PUD MDD DRD 4 Ex3 s $/ 1\{1\}$ & & 0.1210 & 0.0011 * & $0.0002 *$ & $0.0002 *$ & $0.0025 *$ \\
\hline PUD MDD DRD4 Ex3 s/s $\{2\}$ & & & $0.0045 *$ & $0.0041 *$ & $0.0042 *$ & 0.0419 * \\
\hline PUD MDD DRD4 Ex3 1/1 \{3\} & & & & $0.0271 *$ & $0.0226 *$ & 0.0325 * \\
\hline control DRD4 Ex3 s/1 $\{4\}$ & & & & & 0.7281 & 0.9640 \\
\hline control DRD4 Ex3 s/s $\{5\}$ & & & & & & 0.7980 \\
\hline control DRD4 Ex3 1/1 $\{6\}$ & & & & & & \\
\hline
\end{tabular}




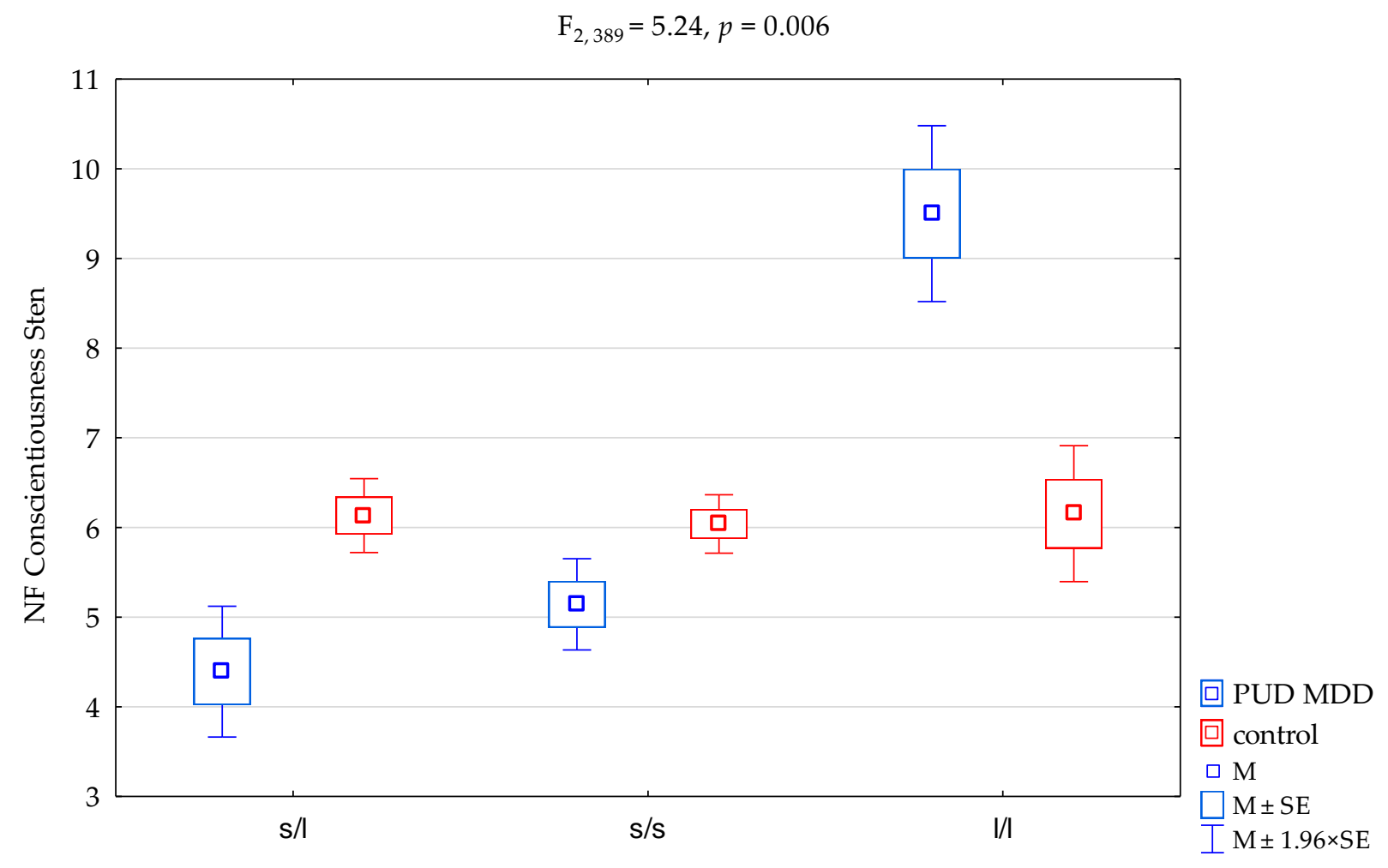

DRD4 Ex3

Figure 2. Interaction between patients with polysubstance use disorder comorbid with a depressive episode (PUD MDD)/control and DRD4 exon 3 (DRD4 Ex3) and the NEO FFI Conscientiousness/scale. M, mean; SE, standard error.

\section{Discussion}

Compared to the controls, we found no statistically significant differences in the genotype frequency for the DRD4 exon 3 (Ex3) gene in the patients diagnosed with PUD MDD and patients diagnosed with PUD.

Overall, a vast variety of clinical genetic linkage studies have explored possible correlations between $D R D 4$ expression and addiction. A study carried out by Shao et al. revealed that a significantly greater cue-induced craving for heroin was found in heroin-dependent Chinese subjects carrying the DRD4 VNTR long-type allele, compared to nondependent controls [19]. A study by Ray et al. revealed a significant, direct path between the DRD4 VNTR genotype and alcohol abuse [20]. A more recent study revealed that the homozygous repeat 7R/7R of $D R D 4$ was significantly associated with substance abuse disorder in Jordan's population [21].

Furthermore, we ask ourselves whether depression is also genetically linked to substance use disorder, especially in the context of the DRD4 gene and its VNTR polymorphic variant in exon 3. A considerable number of studies indicate that there is a link between depression and the dopaminergic system. On the one hand, a meta-analysis of 12 studies of VNTR of the DRD4 gene polymorphism with depression performed by López León et al. (2005) revealed that the short allele 2 is associated with depression [22], but on the other hand, Gafarov et al. [23] found that male carriers of the $4 R / 6 R$ genotype of the $D R D 4$ gene were more likely to be found amongst subjects with a severe level of anxiety and depression and the carriers of the $D R D 4$ allele $6 \mathrm{R}$ were more common among males diagnosed with depression. The number of tandem turns of the VNTR of the DRD4 gene polymorphism was on the increase. The level of vital exhaustion also increased. The authors [23] claim that it is so because amongst people with the long allele of the DRD4 exon 3 polymorphism, the affinity of dopamine with the receptor is reduced, and therefore, that group is less sensitive to dopamine. Hence, there is a high frequency of genotypes with the long allele of the DRD4 exon 3 in males with anxiety, depression, and vital exhaustion. 
The same question was addressed by Bobadilla et al., who conducted their research to find out if the DRD4 gene polymorphism was associated with a comorbidity in relation to depression and marijuana use symptoms in a large, diverse, non-clinical adolescent sample. In the study, they also explored how risk factors previously associated with substance use and depression (ethnicity, age, victimization, and alcohol-related problems) were linked to the co-occurrence of marijuana use and depression [24]. The $\geq 7 \mathrm{R} / \geq 7 \mathrm{R} D R D 4$ genotype significantly heightened the risk of co-occurrent cannabis use and depressive symptoms, which was consistent with the hypothesis. As previously mentioned, a number of studies have linked the $\geq 7 \mathrm{R}$ allele to "less efficient functioning" at the molecular level [24].

Not only did we not confirm such a relationship, but we found something completely different in our study population. A statistically significant difference was shown in the frequency of DRD4 exon 3 (Ex3) alleles between all patients diagnosed with PUD MDD and the controls, but the frequency of 1 alleles was lower in the PUD MDD group vs. controls (Table 3 (1 0.18 vs. $\left.0.25, \chi^{2}=3.99, \mathrm{p}=0.046\right)$ ).

Therefore, we included personality traits in our study. They are believed to play an important role in the case of psychiatric disorders. In various circumstances, each individual's behavior follows particularly distinctive patterns. Personality traits are environmentally and biologically determined [25].

The aim of our study was to find possible associations between personality traits and $D R D 4$ exon 3 gene polymorphisms of male patients with polysubstance use disorder with cooccurrence of a depressive episode, which may present a specific endophenotype of this group of patients.

We found differences in personality traits between PUD MDD subjects, PUD subjects, and controls. PUD patients with a depressive episode delivered higher scores on the Neuroticism and Openness Scale and a higher level of anxiety (STAI trait/state scores) compared to patients with polysubstance use disorder without a depressive episode. Simultaneously, PUD MDD subjects delivered lower scores on the Agreeability and Conscientiousness Scales compared to PUD patients (Table 4). However, extraversion did not differentiate PUD MDD patients from PUD subjects, but it did differentiate both groups from controls (PUDD MD and PUD subjects had lower scores than controls). Our findings are consistent with the findings of other authors that people with substance use disorders have a common personality profile: high neuroticism, low conscientiousness, and low agreeableness [26-28]. In a Norwegian study, the opioid-dependent sample scored higher on neuroticism, lower on extraversion, and lower on conscientiousness compared to controls [29].

Thus, the main findings of our study are the interactions for the groups of PUD MDD subjects vs. controls between the DRD4 genotype and two domains of the five-factor model of personality, i.e., extraversion and conscientiousness. The s/1 heterozygous variants were linked to lower scores on the extraversion and conscientiousness scales-predisposed to be in the PUD MDD group (Figures 1 and 2 and Table 7)—whereas the $1 / 1$ homozygous carriers presented a higher level of extraversion and conscientiousness, predisposed to be in the control group. In our research, $1 / 1$ alleles had a protective effect on the PUD MDD group.

This protective effect of the 1 alleles may be found in our post hoc analysis (Table 7). While in the PUDD MDD group, the mean sten score on the Extraversion Scale was 5.44 (Table 5), in the PUD MDD DRD4 exon 3 (Ex3) 1/1 group, it was 9.0 (Table 7). The same happened for the Conscientiousness Scale: the mean sten score in the PUDD MDD group was 5.01, and in the PUD MDD DRD4 exon 3 (Ex3) 1/1 group, it was 9.5. This effect is presented in Figures 1 and 2. While examining interactions in the subjects with the DRD4 exon 3 (Ex3) s/1 polymorphism, a lower level of extraversion (sten scores) was found compared to the control group with the DRD4 exon 3 (Ex3) s/1 polymorphism. In contrast, an inverse correlation occurs for interactions in individuals with the DRD4 exon 3 (Ex3) 1/1 polymorphism in the level of extraversion (for genotypic correlations in 
the control group, that level of extraversion did not change-as shown in Figure 1, no additive control + genetic polymorphism effect was found).

For interactions in the subjects (patients with polysubstance use disorder comorbid with a depressive episode) with the DRD4 exon 3 (Ex3) s/l polymorphism, a lower level of conscientiousness (sten scores) may be found compared to the control group with the $D R D 4$ exon 3 (Ex3) s/1 polymorphism (4.39 vs. 6.13). In contrast, an inverse correlation occurs for interactions in the subjects with the DRD4 exon 3 (Ex3) 1/1 polymorphism. Their level of conscientiousness (sten scores) is higher than in the control group with the DRD4 exon 3 (Ex3) $1 / 1$ polymorphism ( 9.5 vs. $6.15 ; \mathrm{F}_{2,389}=5.24, p=0.006$ ). Furthermore, the level of conscientiousness in the control group did not change depending on the variant of the $D R D 4$ exon 3 (Ex3) s/l polymorphism (no additive control + genetic polymorphism effect was found) (Figure 2).

Conscientiousness includes good impulse control and goal-directed behaviors, whereas extraversion means talkativeness and assertiveness. A person with low scores on the Extraversion Scale is an introvert. Some studies have documented the association between $D R D 4$ and temperament, or personality traits. Their results suggest that the long allele is linked to high novelty seeking and risk taking, constricted emotional responses, and with preserved attention processing of emotional stimuli and efficient problem solving. This may explain its protective effect observed in our study.

In three high-impact consecutive publications, the long allele of the DRD4 exon 3 polymorphism was correlated with a significant increase in the frequency of novelty seeking $[12,13,30]$. Novelty seeking correlates positively with extraversion and negatively with conscientiousness; therefore, associations between long DRD4 exon 3 alleles and higher extraversion and lower conscientiousness scores were reported respectively using the NEO-PI-R scales [25]. This polymorphism has its effect on exploratory, extraverted, rather than impulsive subtypes of novelty seeking. A number of research studies provided no support for this hypothesis on the association between polymorphisms of the dopamine D4 receptor gene, novelty seeking, and personality [31-34].

However, one should draw no definitive conclusions and be aware of the limitations of the study-i.e., the size of the group and the fact that the genetic aspect was only partially analyzed. In the case of multi-genetic and multi-factorial disorders that we have studied, it is difficult to draw any firm conclusions. Nevertheless, we hope our analysis broadens the view on the biological aspects of these disorders.

\section{Conclusions}

In conclusion, the comparison of patients diagnosed with polysubstance use disorder comorbid with a depressive episode to the control group of healthy volunteers shows that the former delivered significantly higher scores on both the STAI state and trait scale and the NEO-FFI Neuroticism and Openness Scale, and lower scores on the Extraversion, Agreeability, and Conscientiousness NEO-FFI Scales. In the DRD4 exon 3 (Ex3) gene polymorphism, the s allele was more frequent in the study group, and the 1 allele was less frequent. In our research study, $1 / 1$ alleles exerted a protective effect on the PUD MDD group. This protective effect was mediated by the fact that the $1 / 1$ homozygous carriers had a higher level of extraversion and conscientiousness. Our findings contradict a number of studies which confirmed associations between the $7 \mathrm{R}$ and an increased risk of various neuropsychiatric disorders, including depression and anxiety. This contradiction may suggest that it is better to conceptualize the $D R D 4$ gene as a plasticity gene whose effect may point to either positive or negative dependence on particular environments. According to Jiang, the role of $\mathrm{D} 4$ receptor gene exon 3 polymorphisms is to shape a prosocial behavior and altruism. Differential susceptibility alleles may be more prosocial if they are influenced by one environment, and less prosocial in another [35].

These associations reveal that psychological factors combined with genetic data identify a new area of research on addiction, including the problem of diagnosis. However, we want to be careful and draw no definite conclusions at this stage of our research. 
Author Contributions: Conceptualization, A.G. and K.C.; methodology, J.C. and K.C.; software, K.C.; validation, J.C., K.C. and W.M.; formal analysis, A.G. and K.C.; investigation, J.M.; resources, J.M. and W.M.; data curation, J.M. and J.C.; writing-original draft preparation, J.C., J.M., A.G., K.C., P.K., M.C., E.S., M.Ś. and T.P.; writing-review and editing, J.M., A.G., K.C., J.C. and T.P; visualization, K.C.; supervision, A.G.; project administration, A.G.; funding acquisition, A.G. All authors have read and agreed to the published version of the manuscript.

Funding: This research was funded by the National Science Center, Poland (grant number UMO2015/19/B/NZ7/03691).

Institutional Review Board Statement: The study was conducted in accordance with the Declaration of Helsinki principles and approved by the Bioethics Committee of the Pomeranian Medical University in Szczecin (KB-0012/106/16).

Informed Consent Statement: All subjects provided written informed consent for participating in the research.

Data Availability Statement: Not applicable.

Conflicts of Interest: The authors declare no conflict of interest.

\section{References}

1. McCabe, S.E.; West, B.T.; Jutkiewicz, E.M.; Boyd, C.J. Multiple DSM-5 substance use disorders: A national study of US adults. Hum. Psychopharmacol. Clin. Exp. 2017, 32, e2625. [CrossRef]

2. McHugh, R.K.; Votaw, V.R.; Sugarman, D.E.; Greenfield, S.F. Sex and gender differences in substance use disorders. Clin. Psychol. Rev. 2018, 66, 12-23. [CrossRef]

3. Bahorik, A.L.; Leibowitz, A.; Sterling, S.A.; Travis, A.; Weisner, C.; Satre, D.D. Patterns of marijuana use among psychiatry patients with depression and its impact on recovery. J. Affect. Disord. 2017, 213, 168-171. [PubMed]

4. Bahji, A.; Mazhar, M.N.; Hudson, C.C.; Nadkarni, P.; MacNeil, B.A.; Hawken, E. Prevalence of substance use disorder comorbidity among individuals with eating disorders: A systematic review and meta-analysis. Psychiatry Res. 2019, 273, 58-66. [CrossRef] [PubMed]

5. Lai, J.H.; Zhu, Y.S.; Huo, Z.H.; Sun, R.F.; Yu, B.; Wang, Y.P.; Li, S.B. Association study of polymorphisms in the promoter region of DRD4 with schizophrenia, depression, and heroin addiction. Brain Res. 2010, 1359, 227-232. [CrossRef] [PubMed]

6. Masiak, J.; Chmielowiec, J.; Chmielowiec, K.; Grzywacz, A. DRD4, DRD2, DAT1, and ANKK1 Genes Polymorphisms in Patients with Dual Diagnosis of Polysubstance Addictions. J. Clin. Med. 2020, 9, 3593. [CrossRef]

7. Van Tol, H.H.; Wu, C.M.; Guan, H.C.; Ohara, K.; Bunzow, J.R.; Civelli, O.; Kennedy, J.; Seeman, P.; Niznik, H.B.; Jovanovic, V. Multiple dopamine D4 receptor variants in the human population. Nature 1992, 358, 149-152.

8. Asghari, V.; Sanyal, S.; Buchwaldt, S.; Paterson, A.; Jovanovic, V.; Van Tol, H.H. Modulation of intracellular cyclic AMP levels by different human dopamine D4 receptor variants. J. Neurochem. 1995, 65, 1157-1165. [CrossRef]

9. Vandenbergh, D.J.; Rodriguez, L.A.; Hivert, E.; Schiller, J.H.; Villareal, G.; Pugh, E.W.; Uhl, G.R. Long forms of the dopamine receptor (DRD4) gene VNTR are more prevalent in substance abusers: No interaction with functional alleles of the catechol-omethyltransferase (COMT) gene. Am. J. Med. Genet. 2000, 96, 678-683. [CrossRef]

10. Munafò, M.R.; Yalcin, B.; Willis-Owen, S.A.; Flint, J. Association of the dopamine D4 receptor (DRD4) gene and approach-related personality traits: Meta-analysis and new data. Biol. Psychiatry 2008, 63, 197-206. [CrossRef]

11. Eisenberg, D.T.; MacKillop, J.; Modi, M.; Beauchemin, J.; Dang, D.; Lisman, S.A.; Wilson, D.S. Examining impulsivity as an endophenotype using a behavioral approach: A DRD2 TaqI A and DRD4 48-bp VNTR association study. Behav. Brain Funct. 2007, 3, 1-14. [CrossRef]

12. Benjamin, J.; Li, L.; Patterson, C.; Greenberg, B.D.; Murphy, D.L.; Hamer, D.H. Population and familial association between the D4 dopamine receptor gene and measures of novelty seeking. Nat. Genet. 1996, 12, 81-84. [CrossRef]

13. Ebstein, R.P.; Novick, O.; Umansky, R.; Priel, B.; Osher, Y.; Blaine, D.; Belmaker, R.H. Dopamine D4 receptor (D4DR) exon III polymorphism associated with the human personality trait of novelty seeking. Nat. Genet. 1996, 12, 78-80. [CrossRef] [PubMed]

14. Schinka, J.A.; Letsch, E.A.; Crawford, F.C. DRD4 and novelty seeking: Results of meta-analyses. Am. J. Med. Genet. 2002, 114, 643-648. [CrossRef] [PubMed]

15. Strobel, A.; Lesch, K.P.; Jatzke, S.; Paetzold, F.; Brocke, B. Further evidence for a modulation of Novelty Seeking by DRD4 exon III, 5-HTTLPR, and COMT val/met variants. Mol. Psychiatry 2003, 8, 371-372. [CrossRef] [PubMed]

16. Penke, L.; Denissen, J.J.; Miller, G.F. The evolutionary genetics of personality. Eur. J. Personal. 2007, 21, 549-587. [CrossRef]

17. Kotov, R.; Gamez, W.; Schmidt, F.; Watson, D. Linking “big” personality traits to anxiety, depressive, and substance use disorders: A meta-analysis. Psychol. Bull. 2010, 136, 768. [CrossRef]

18. Costa, P.; McCrae, R.R. The Revised NEO Personality Inventory (NEO-PI-R); Sage Publications Inc.: Thousand Oaks, CA, USA, 2008; Volume 2, pp. 179-198. 
19. Shao, C.; Li, Y.; Jiang, K.; Zhang, D.; Xu, Y.; Lin, L.; Wang, Q.; Zhao, M.; Jin, L. Dopamine D4 receptor polymorphism modulates cue-elicited heroin craving. Chin. Psychopharmacol. 2006, 186, 185-190. [CrossRef]

20. Ray, L.A.; Bryan, A.; Mackillop, J.; McGeary, J.; Hesterberg, K.; Hutchison, K.E. The dopamine D receptor (DRD4) gene exon III polymorphism, problematic alcohol use and novelty seeking: Direct and mediated genetic effects. Addict. Biol 2009, 14, 238-244. [CrossRef]

21. AL-Eitan, L.N.; Alshudaifat, K.M.; Anani, J.Y. Association of the DRD4 exon III and 5-HTTLPR VNTR polymorphisms with substance abuse in Jordanian Arab population. Gene 2020, 733, 144267. [CrossRef]

22. López, L.S.; Sayed-Tabatabaei, F.A.; Croes, E.A. The dopamine D4 receptor gene 48-base-pair-repeat polymorphism and mood disorders: A meta-analysis. Biol. Psychiatry 2005, 57, 999-1003. [CrossRef]

23. Gafarov, V.; Gromova, E.; Maximov, V.; Bakulin, I.; Gafarova, A. Association of Personal Anxiety with Dopamine Receptor D4 (DRD4), DAT Genes Polymorphism. Anxiety Disord.-New Achiev. 2020. [CrossRef]

24. Bobadilla, L.; Vaske, J.; Asberg, K. Dopamine receptor (D4) polymorphism is related to comorbidity between marijuana abuse and depression. Addict. Behav. 2013, 38, 2555-2562. [CrossRef] [PubMed]

25. Gescher, D.M.; Kahl, K.G.; Hillemacher, T.; Frieling, H.; Kuhn, J.; Frodl, T. Epigenetics in personality disorders: Today's insights. Front. Psychiatry 2018, 9, 579. [CrossRef]

26. Carter, J.A.; Herbst, J.H.; Stoller, K.B.; King, V.; Kidorf, M.S.; Costa, P.T.; Brooner, R.K. Short-term stability of NEO-PI-R personality trait scores in opioid-dependent outpatients. Psychol Addict Behav. 2001, 15, 255-260. [CrossRef] [PubMed]

27. Brooner, R.K.; Schmidt, C.W.; Herbst, J.H. Personality trait charcteristics of opioid abusers with and without comorbid personality disorders. In Personality Disorders: And the Five-Factor Model of Personality; Costa, P.T., Widiger, T.A., Eds.; American Psychological Association: Washington, DC, USA, 2002.

28. Piedmont, R.L.; Ciarrocchi, J.W. The utility of the revised NEO personality inventory in an outpatient, drug rehabilitation context. Psychol. Addict Behav. 1999, 13, 213-226. [CrossRef]

29. Kornør, H.; Nordvik, H. Five-factor model personality traits in opioid dependence. BMC Psychiatry 2007, 7, 37. [CrossRef]

30. Strobel, A.; Wehr, A.; Michel, A. Association between the dopamine D4 receptor (DRD4) exon III polymorphism and measures of Novelty Seeking in a German population. Mol. Psychiatryn 1999, 4, 378-384. [CrossRef] [PubMed]

31. Ekelund, J.; Suhonen, J.; Järvelin, M.R.; Peltonen, L.; Lichtermann, D. No association of the $-521 \mathrm{C} / \mathrm{T}$ polymorphism in the promoter of DRD4 with novelty seeking. Mol. Psychiatry 2001, 6, 618-619. [CrossRef] [PubMed]

32. Strobel, A.; Lesch, K.P.; Hohenberger, K.; Jatzke, S.; Gutzeit, H.O.; Anacker, K.; Brocke, B. No association between dopamine D4 receptor gene exon III and -521C/T polymorphism and novelty seeking. Mol. Psychiatry 2002, 7, 537-538. [CrossRef]

33. Jönsson, E.G.; Ivo, R.; Gustavsson, J.P.; Geijer, T.; Forslund, K.; Mattila-Evenden, M.; Rylander, G.; Cichon, S.; Propping, P.; Bergman, H.; et al. No association between dopamine D4 receptor variants and Novelty Seeking. Mol. Psychiatry 2002, 7, 18-20. [CrossRef] [PubMed]

34. Strobel, A.; Spinath, F.M.; Angleitner, A.; Riemann, R.; Lesch, K.P. Lack of Association between Polymorphisms of the Dopamine D4 Receptor Gene and Personality. Neuropsychobiology 2003, 47, 52-56. [CrossRef] [PubMed]

35. Jiang, Y.; Chew, S.H.; Ebstein, R.P. The role of D4 receptor gene exon III polymorphisms in shaping human altruism and prosocial behavior. Front. Hum. Neurosci. 2013, 7, 195. [CrossRef] [PubMed] 